and regained normal immunity to ensure success. In agreement with other authors, ${ }^{1}$ we never found that cervicothoracic access was not needed for simple repair of a TEF. Thus the risks of postoperative assisted ventilation (which constitute the main cause of relapse) are greatly reduced, resulting in an acceptable rate of mortality (about $10 \%$ according to Marzelle and associates ${ }^{1}$ ).

A left lateral cervical incision gives very satisfactory access for simple closure of a TEF, with better visibility and adequate operative space compared with the median approach, and has the advantage of being able to be transformed to a cervical incision at the neck if necessary. Placement of a muscular flap between the two viscera is another indispensable element for success. The partial relapse in our second patient was due, in our opinion, to the insertion of a muscular flap that was too thin (omohyoidal muscle).

In cases of associated tracheal stenosis, which occurs in about $22 \%$ of patients with a TEF, ${ }^{1}$ the possible anastomotic resection of even a small scgment (a rare event) greatly incrcases the surgical risk. For this reason, in two of our patients with associated tracheal lesions, we opted for treatment with a dilating endoprosthesis.

\section{REFERENCES}

1. Marzelle J, Dartevelle P, Khalife J, Rojas Miranda A, Chapelier A, Levasseur P. Surgical management of acquired postintubation tracheo-oesophageal fistulas: 27 patients. Eur J Cardiothoracic Surg 1989;3:499-502.

2. Leeds WM, Morley TF, Zappasodi SJ, Giudice JC. Computed tomography for diagnosis of tracheoesophageal fistula. Crit Care Med 1986;14:591-2.

3. White RE, Ianettoni MD, Orringer MB. Thoracic esophageal perforation. J Interthorac Cardiovasc Surg 1995;109: $140-6$.

\title{
SURGICAL CORRECTION OF THE HYPOPLASTIC AORTIC ARCH BY THE SUBCLAVIAN FREE FLAP METHOD IN THE NEONATE
}

Hiroshi Kubota, MD, Lionel Camilleri, MD, Benoît Legault, MD, Bruno Miguel, MD, Ahmed Tahir El Youssoufi, MD, Patrick Bailly, MD, Isabelle Brazzalotto, MD, Stéphane Helfter, MD, Jean-René Lusson, MD, and Charles de Riberolles, MD, Clermont-Ferrand, France

Although several surgical techniques for treatment of aortic arch hypoplasia associated with coarctation of the aorta have been described, the most appropriate method is still controversial. Here we report a technique using a subclavian free flap to enlarge the hypoplastic transverse aorta.

Clinical summary. A femalc infant, in the thirty-eighth gestational week, was found by predelivery echocardiography to have a hypoplastic left heart and aortic coarctation. On the first day, the infant, weighing $3440 \mathrm{~g}$, was confirmed to have this condition along with tubular hypoplasia of the transverse aortic arch. On the third day,

From the Department of Cardiovascular Surgery, Department of Anesthesia, Department of Cardiology, University of Clermont-Ferrand, Clermoni-Ferrand, France.

Received for publication Feb. 12, 1998; accepted for publication March 18, 1998.

Address for reprints: Charles de Riberolles, MD, Department of Cardiovascular Surgery, Hôpital Gabriel Montpied, University of Clermont-Ferrand, B.P. 69, 63003, Clermont-Ferrand, Cedex 1, France.

J Thorac Cardiovase Surg 1998;116:519-21

Copyright $(\mathcal{C} 1998$ by Mosby, Inc.

$0022-5223 / 98 \$ 5.00+0 \quad 12 / 54 / 90506$ she underwent surgical treatment through a left posterolateral thoracotomy.

The upper half of the descending thoracic aorta and the transverse aortic arch were dissected and exposed. The left common carotid artery and the left subclavian artery were then mobilized along their entire intrathoracic course. The distance between the origin of the brachiocephalic artery and the origin of the left common carotid artery was longer than normal. The origins of the carotid artery and the left subclavian artery were also rather distant. The diameters of the ascending aorta just proximal to the brachiocephalic artery, transverse aortic arch, and descending aorta were $6.5 \mathrm{~mm}, 3 \mathrm{~mm}$, and $7 \mathrm{~mm}$, respectively. The transverse arch/ascending aorta diameter ratio was 0.46 , and the transverse arch/descending aorta diameter ratio was 0.43 . A proximal vascular occlusive clamp was placed at the origin of the brachiocephalic artery as far to the right side as possible, and the appropriate arterial perfusion was judged from the right radial arterial pressure. The left carotid artery was snared, and the isthmic aorta was clamped proximal to the patent ductus. After two branches had been treated, the left subclavian artery was ligated as distally as possible and excised from its origin. The distal arch was then cut proximal to the left subclavian artery, and the inferior side of the transverse aortic arch was incised as proximally as possible (Fig. 1, A). The longitudinally opened subclavian 

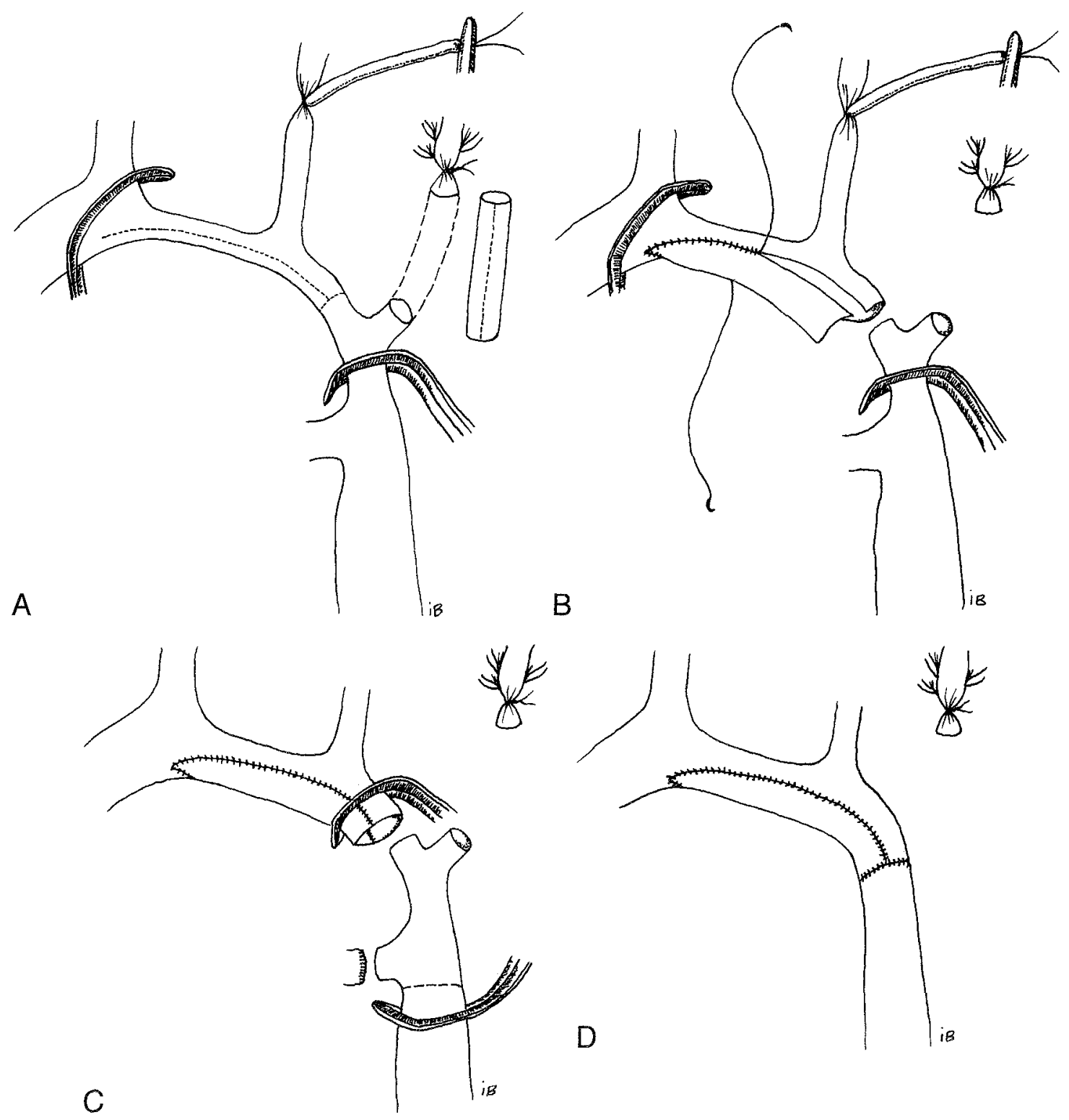

Fig. 1. A, Two clamps wcre placed on the aorta, and the left carotid artery was snared. The left subclavian artery was excised from its origin and incised longitudinally for use as a free flap. $\mathbf{B}$, The subclavian free flap was sutured to the incised transverse aortic arch with 7-0 polydioxanone. $\mathbf{C}$, Coarctectomy. D, End-to-end anastomosis.

free flap was then sutured to enlarge the transverse aorta with a single running suture of 7-0 polydioxanone (PDS, Ethicon, Inc., Somerville, N.J.). This absorbable stiture was used to prevent secondary growth failure (Fig. $1, B$ ). The proximal clamp was then moved to the distal aortic arch and the distal clamp to the descending aorta. The patent ductus artcriosus was ligated and divided, and the coarctation was resccted along with the origin of the lcft subclavian artery (Fig. 1,C). An end-to-end anastomosis was created with 7-0 polydioxanone suture (Fig. 1,D).
The early postoperative course was uneventful, and no neurologic complications were seen. The femoral pulse was well palpable. Postoperative echocardiography showed a well-enlarged aortic arch, and no pressurc gradient was detected in the aortic arch and the distal anastomosis. However, echocardiography performed 2 months after the operation showcd severe stenosis at the site of the distal anastomosis. Balloon angioplasty was therefore performed 3 months after the operation. The stenosis was successfully dilated, and the pressure gradi- 
ent decreased: peak systolic pressure, 56 to $33 \mathrm{~mm} \mathrm{Hg}$; mean 29 to $14 \mathrm{~mm} \mathrm{Hg}$ (Fig. 2).

Discussion. In patients with aortic coarctation and a hypoplastic aortic arch from the brachiocephalic artery down to the isthmus, prevention of residual obstruction reduces mortality in the early postoperative period and also allows normal growth of the aortic arch. If only the isthmic lesion is treated, leaving a long restricted aortic segment, spontaneous growth of the hypoplastic arch is usually inadequate. Therefore hypoplasia of the transverse aortic arch necds to be corrected. Several kinds of surgical treatment for this anomaly, such as extended end-to-end anastomosis, reversed subclavian flap angioplasty, and the combined resection-flap procedure, have been described. ${ }^{1-3}$ Each has certain advantages and limitations.

The first description of extended resection and anastomosis of the distal aorta to the undersurface of the aortic arch was given by Amato, Rheinlander, and Cleveland. ${ }^{1}$ This technique allows excellent reconstruction of the arch but requires more time and extensive dissection, including the possibility of dividing the intercostal arteries to allow good mobilization. When extended end-to-end anastomosis, as described by Lacour-Gayet and associates, ${ }^{4}$ is used, two possible problems may arise: (1) If the aortic opening is insufficient, the risk of residual proximal obstruction increases, and (2) if mobilization of the aorta is insufficient, it may be difficult to approximate the two clamps. Compared with extended end-to-end anastomosis, our technique has certain advantages: (1) Aggressive dissection of the descending aorta is not required, (2) the tension on the anastomosis is reduced, and (3) the ischemic time of the lower body is thought to be shorter because the blood flow of the descending aorta is supplied from the patent ductus arteriosus during reconstruction of the aortic arch. Both the reversed subclavian flap and the free subclavian flap techniques are limited to some extent by the length of the subclavian flap. However, in the case of the reversed flap the distal extent of the flap is fixed, whereas with the free flap method it can be brought more proximally and a beveled anastomosis can then be made. This serves to reduce tension on the anastomosis relative to the standard extended resection and end-to-end anastomosis. The limitations of our technique are as follows: (1) The diameter of the new transverse aortic arch depends on the size of the left subclavian artery, and (2) the length of the new transverse aortic arch depends on the length of the harvested left subclavian artery. However, these factors were not disadvantageous in the present case. Mobilization of the cntire intrathoracic course of the left subclavian artery provided enough length for reconstruction of the aortic arch. The diameter of the new aortic arch was thought to be adequate, because no pressure gradient was detected after the operation. In addition, autologous fresh arterial tissues

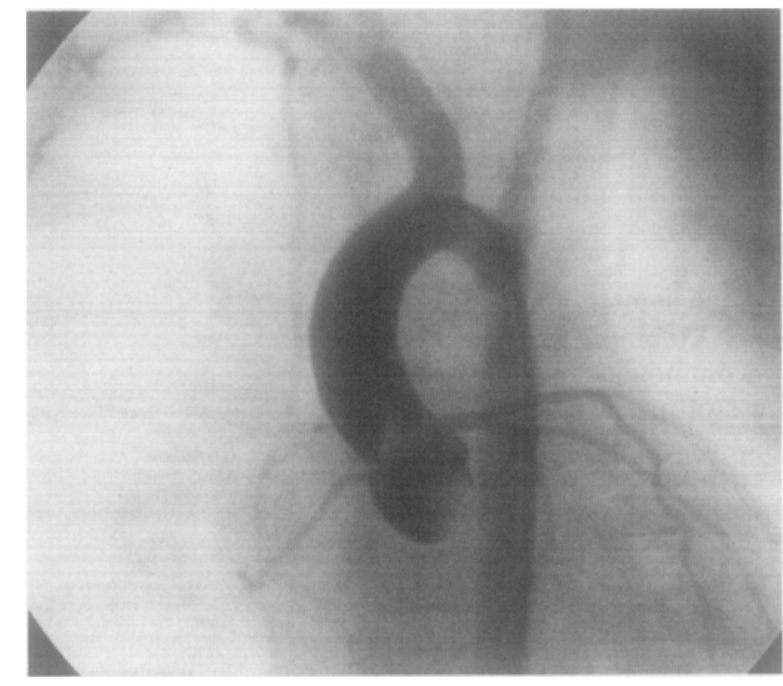

Fig. 2. Aortography after balloon angioplasty. The transverse aortic arch is well enlarged. Mild stenosis can be seen at the distal anastomosis.

are theorctically better than foreign material for arterial reconstruction because of their potential for growth. The risks of aneurysm formation and infection are also minimized. For these reasons, our technique may be applicable to infants with "severe" arch hypoplasia with arch indices of 0.25 or less. "Unfortunately, severe stenosis at the distal anastomosis was discovered in this case. Residual ductal tissue may have been present in the descending aorta and developed gradually. Balloon angioplasty was effective, but conclusions about the long-term effectiveness of this technique will require further follow-up and more cases.

\section{REFERENCES}

1. Amato JJ. Rheimlander HF, Cleveland RJ. A method of enlarging the distal transverse arch in infants with hypoplasia and coarctation of the aorta. Ann Thorac Surg 1977;23:261-3.

2. Elliott MJ. Coarctation of the aorta with arch hypoplasia: improvements on a new technique. Ann Thorac Surg 1987;44: 321-3.

3. Hart JC, Waldhausen JA. Reversed subclavian flap angioplasty for arch coarctation of the aorta. Ann Thorac Surg 1983;36:715-7.

4. Lacour-Gayet F, Bruniaux I, Serraf A, et al. Hypoplastic transverse arch and coarctation in neonates: surgical reconstruction of the aortic arch-a study of sixty-six patients. J Thorac Cardiovase Surg 1990;100:808-16.

5. Siewers RD, Ettedgui J, Pahl E, Tallman T, del Nido PJ Coarctation and hypoplasia of the aortic arch: Will the arch grow? Ann Thorac Surg 1991;52:608-14. 